\section{A Whole-tree System for Gas-exchange Studies}

Luca Corelli-Grappadelli and E. Magnanini

Istituto di Coltivazioni Arboree, Universitá di Bologna, V. Filippo Re 6, 40126

Bologna, Italy

Additional index words. photosynthesis

\begin{abstract}
Based on a commercially available net photosynthesis (Pn) unit coupled to a custom-built chamber that does not require air conditioning, a low-cost system to measure whole-tree gas exchange in the field is described. The temperature in the chamber is influenced by air flow in relation to tree size. A flow of 20 liters $\cdot \mathrm{s}^{-1}$ (equal to $\approx 1.5$ chamber volume changes/min) was sufficient to maintain the leaves of an 11-year-old 'Golden Delicious'/M.27 tree at a temperature similar to that of the ambient air and control $\mathrm{CO}_{2}$ gradients in the chamber. The system has been in operation on apple (Malus domestica Borkh.) trees for up to 4 months without modifying tree behavior.
\end{abstract}

The advent of affordable portable gas exchange units has made possible detailed studies of leaf photosynthesis in the field, studies that are often more meaningful than those conducted in the laboratory. Yet, the fact that these units measure individual-leaf gas exchange only is a major limitation when wholeplant productivity is of interest. Whole-plant productivity is influenced greatly by canopy complexity and growth, which, in turn, make it essentially impossible to measure all of the leaves individually. A common solution to this problem is to take readings from a sample of leaves, and then model the canopy response based on individual-leaf data and environmental characteristic estimates (especially radiation) in the canopy.

An alternative approach is to use large chambers that enclose the whole tree. In this case, however, gas exchange of a complex of respiratory and photosynthetic organs is studied, not just that of a collection of leaves. Therefore, shifting the focus from a single leaf to the whole canopy entails more than a simple measurement scale change, a fact that should be kept in mind when evaluating the results obtained from such a system. In general, tree chambers are complex and often expensive. Of primary importance is controlling temperature and $\mathrm{CO}_{2}$ gradients, as changes in these variables may affect physical conditions such as humidity and atmosphere composition at the leaf surface and photosynthesis and respiration in the enclosed plant parts (Flore and Lakso, 1990). Further, the chamber wall's transmission properties can affect the light environment within, reducing incident radiation intensity and changing light quality and the direct : diffuse radiation ratio.

Heinicke and Childers (1937) constructed

Received for publication 5 May 1992. Accepted for publication 29 Sept. 1992. Research supported by the National Research Council of Italy, Special cost of publishing this paper was defrayed in part by the payment of page charges. Under postal regulations, this paper must therefore be hereby marked advertisement solely to indicate this fact. and used an assimilation chamber to study apple tree gas exchange in the field. Their design called for a tree glasshouse in which $\mathrm{CO}_{2}$ exchange was measured by trapping the gas from the ingoing and outgoing air streams in a $\mathrm{KOH}$ solution, followed by titration. The chamber's air temperature was controlled and maintained within 1 to $2 \mathrm{C}$ of ambient temperature by a refrigeration unit driven by a simple, positions referred to in Table 2. Project RAISA, subproject no. 2, paper no. 756 . The custom-built thermostat that compared the internal and external air temperature, a feature that is still desirable. The trapping and titration procedures, however, were time consuming, and long runs of several hours were necessary to quantify the tree's $\mathrm{CO}_{2}$ uptake.

A large plastic whole-tree chamber that used infrared gas analyzers to determine $\mathrm{CO}_{2}$ exchange for a full-sized apple tree was constructed by Sirois and Cooper (1964). Their system relied on large-capacity blowers (i.e., high turnover rate) to keep the chamber's air temperature from increasing excessively. The thickness $(4 \mathrm{~mm})$ of the polyethylene used probably affected the amount of light available to the tree, as indicated by the fact that the highest light readings reported during a summer only slightly exceeded $86,0001 \times(\approx 75 \%$ of full sun).

More recently, whole-tree systems have been constructed for air pollution (Adaros et al., 1989; Heagle et al., 1973; Weinstock et al., 1982), and temperature studies (Snelgar et al., 1988), but they were not specifically designed for $\mathrm{CO}_{2}$ and $\mathrm{H}_{2} \mathrm{O}$ exchange studies. Wibbe and Lenz (1989) described a system for whole-tree gas-exchange studies. Yet, because their system involves a bulky apparatus and requires potted plants, it is not movable nor compatible with orchard use. An open system (for two field trees) that uses acetate for the chamber

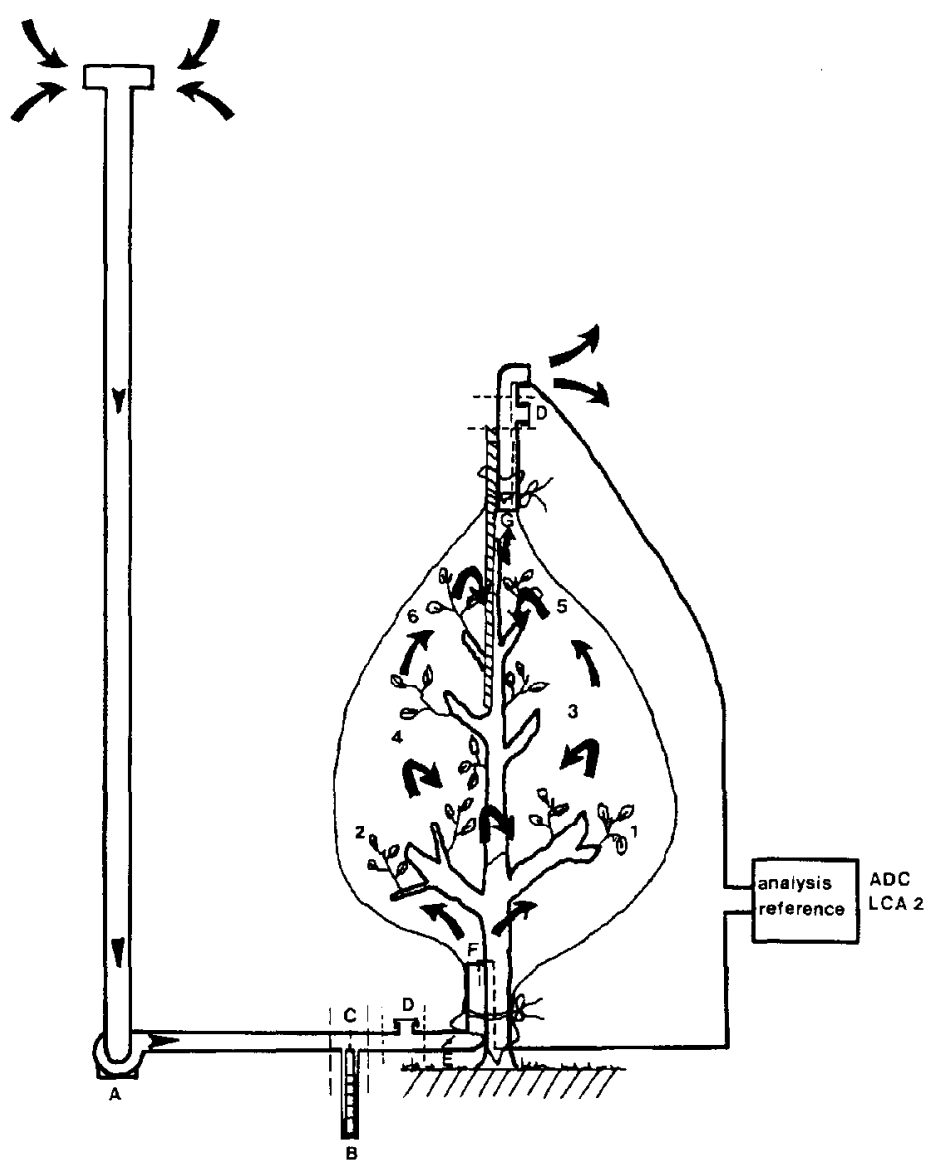

Fig. 1. System profile: the components are lettered as follows: A) AC fan; B) differential air pressure gauge; C) flow restriction; D) chamber inlet (bottom) and outlet (top) access ports for measuring temperature and relative humidity; E) butterfly valve for regulating flow; F) chamber inlet and G) outlet, both fitted with an air-feed line to the ADC LCA 2 infrared gas analyzer. Numbers within the chamber indicate 
was constructed at the East Malling Research Station, East Malling, Kent, England (J.W. Palmer, personal communication). Its main features are an air conditioner that controls temperature and air humidity, and a personal computer (PC) that serves as a control unit and data logger for continuous day and night data collection. A similar system has been built at the Univ. of Bologna, Italy (E.M., unpublished). This system relies on high flow rates to control temperature, rather than on air conditioning, and uses thin polyethylene, instead of acetate, for the chamber. Carbon dioxide concentrations are monitored by an infrared gas analyzer that is automatically calibrated every $2 \mathrm{~h}$. The system is controlled and operated by a PC, which also serves as a data logger. The automation afforded by both systems, however, is complex and expensive.

This paper describes a whole-tree chamber designed to eliminate the need for an air conditioner, reduce the size of the apparatus, and improve the system's mobility. The latter is achieved by using a commercially available portable gas-exchange unit coupled to a custom-made chamber, thereby creating a semiportable open system for whole-tree gas exchange studies in the field.

1) Describing the system and its operation. The system features a portable infrared gas analyzer [LCA2; Analytical Development Co. (ADC), Hoddesdon, U.K.] and a Parkinson leaf chamber for broad leaves (ADC PLC-B) linked to a custom-made whole-tree chamber (Fig. 1). The whole-tree chamber consists of two 0.025 -mm-thick transparent polyethylene sheets that are folded and sealed together to enclose the tree. The configuration is conical, tapering toward the outlet to prevent bulging and, hence, reduce air circulation. It is secured at the top to a support post and the air-outlet pipe and at the bottom to the trunk and air-inlet pipe. Paper or foam rubber gasket material seals the gaps at the post, trunk, and pipes. The apparatus (Figs. 1 and 2) includes an alternating current $(\mathrm{AC})$ air-feed fan, a flow meter, PLC-B access ports to measure temperature and relative humidity $(\mathrm{RH})$, a butterfly valve for flow control, and two small lines feeding inlet- and outlet-air samples (bottom and top, respectively) to the infrared gas analyzer (IRGA) reference and analysis channels. The photosynthetically active radiation (PAR) sensor mounted on the PLC-B can be used to monitor light levels.

Collecting data The data collection system is an open system in which air temperature, $\mathrm{RH}$, and $\mathrm{CO}_{2}$ concentration are measured at the chamber's inlet and outlet. The access ports are each fitted with a plastic adaptor on which the PLC-B is mounted, thereby enabling its sensors to measure. RH and temperature (Fig. 2). The PLC-B inlet and outlet tubes are not connected to any line, thereby allowing a net flux through the chamber. The readings are taken by first mounting the PLC-B to the inlet and then to the outlet line, each time recording $\mathrm{RH}$, temperature, and reference and analysis $\mathrm{CO}_{2}$ concentrations. The inlet and outlet values constitute a complete set of readings. The absolute water content of the air is determined from $\mathrm{RH}$ and air temperature data measured at the inlet and outlet (Long and Hallgren, 1985). By subtracting the inlet value from the outlet value, transpiration rate can be determined. The IRGA is continuously connected to the inlet and outlet lines to read the differential $\mathrm{CO}_{2}$ concentration, regardless of where the PLC-B is positioned. Using the LCA2 fitted with the data logger (ADC-DL1), the data are uploaded to a PC by a BASIC program. Light levels can be monitored by exposing the PLCB's PAR sensor to the incoming radiation, an operation that is best accomplished while reading air temperature and $\mathrm{RH}$ at the outlet, because, being above the canopy, this site is unobstructed. A more accurate measure of the light intensity available to the tree can be obtained by fitting a tape-reinforced slot in the chamber wall with an open-ended plastic bag that provides a resealable access tube to the chamber's interior. Through such openings, internal light readings may be taken, individual leaf Pn measured, or other tasks performed, including shoot positioning and fruit removal.

Measuring air flow. Air flow can be measured in several ways, including mass flow units, hot-wire anemometers, or vane anemometers (Grace, 1989). Also, methods based on flow restriction (Osborne, 1977), or dilution of a known amount of gas in the flow stream can be used to this effect. The mass flow approach is the best method because of its precision, although a unit that accurately measures the high flows required is expensive. Hot-wire and vane anemometers require calibration and are affected by piping geometry (i.e., distance from blower, or from any cause of flow distortion in the pipe, since the flow must be assumed to be laminar), air velocity in the pipe, and air temperature. The hot-wire anemometer gives accurate readings at air velocities in the pipe from 0.1 to $5 \mathrm{~m} \cdot \mathrm{s}^{-1}$, while the vane anemometer requires higher velocities ( 1 to $\left.10 \mathrm{~m} \cdot \mathrm{s}^{-1}\right)$ to be in the linear response range (Grace, 1989). In addition, since air velocity varies between the center and the pipe walls, accurate positioning of both anemometers, particularly the hot-wire anemometer, is necessary to take reliable readings. Air temperature affects its density; this is reflected in the pipe's air velocity. The $\approx 1.5 \%$ difference in density between dry air and fully saturated air at 30C, however, is normally considered acceptable in fan calibration (Osborne, 1977).

The two methods suggested here are recommended for their simplicity. The first uses an air-inlet restriction (Fig. 2C), which produces a differential in the static pressure that is proportional to the air flow, the ratio between the orifice and the pipe cross-sectional area, and the air density. Certain restrictions as to orifice position and dimension relative to fan position and duct geometry also apply (Osborne, 1977). By measuring the static pressure differential across the restriction by a differential pressure gauge, the flow can be calculated as follows (Osborne, 1977): $Q=C_{d}$ a $\sqrt{ }\left\{2 \Delta \mathrm{p} /\left[\rho\left(1-\left(\mathrm{a}^{2} / \mathrm{A}^{2}\right)\right]\right\}\right.$ where $\mathrm{Q}=$ air flow
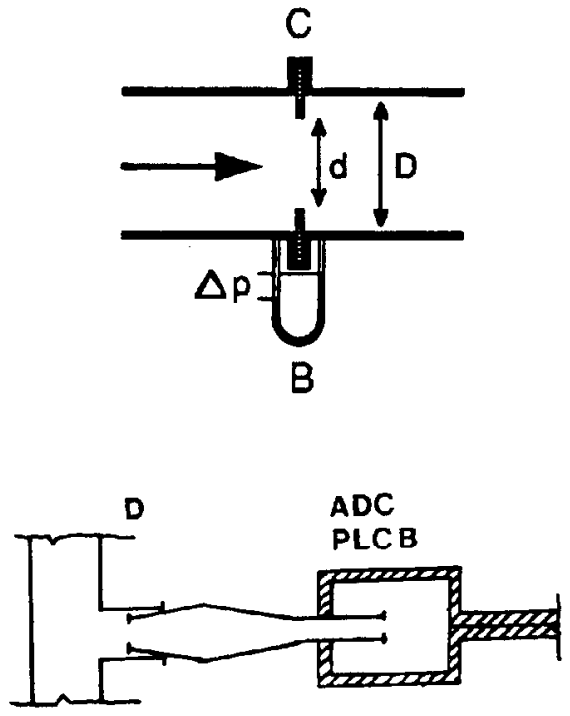

Fig. 2. Flow restriction details and differential air pressure gauge for measuring flow (top), and access port, adaptor, and PLC-B assembly for measuring relative humidity and temperature (bottom).

(liter $\left.\cdot \mathrm{s}^{-1}\right) ; \mathrm{C}_{\mathrm{d}}=$ discharge coefficient [function of the ratio $(\mathrm{a} / \mathrm{A})^{2}$, derived from standard curves]; $a=$ orifice cross-sectional area $\left(\mathrm{mm}^{2}\right)$; $\mathrm{A}=$ pipe cross-sectional area $\left(\mathrm{mm}^{2}\right) ; \rho=$ air density $\left(\mathrm{g} \cdot \mathrm{m}^{-3}\right)$; and $\Delta \mathrm{p}=$ static pressure differential (millimeters of water).

Alternatively, pure $\mathrm{CO}_{2}$ may be bled into the inlet-line air stream. The known flow from the bottle and the change in $\mathrm{CO}_{2}$ concentration caused by the amount of gas supplied make it possible to calculate the flow (when the volume of $\mathrm{CO}_{2}$ added is $<1 / 1000$ of the inlet-air stream) as follows: Flow $_{\mathrm{ch}}=\mathrm{Flow}_{\text {bottle }} / \Delta\left[\mathrm{CO}_{2}\right]$ where $\Delta\left[\mathrm{CO}_{2}\right]=$ change in $\mathrm{CO}_{2}$ concentration caused by adding $\mathrm{CO}_{2}$ to the inlet-air stream $\left(\mathrm{ml} \cdot\right.$ liter $\left.^{-1}\right) ; \mathrm{Flow}_{\text {botle }}=$ flow from the pure $\mathrm{CO}_{2}$ bottle (liter $\cdot \mathrm{s}^{-1}$ ); and $\mathrm{Flow}_{\mathrm{ch}}=$ flow through the system (liter $\cdot \mathrm{s}^{-1}$ ).

Controlling and measuring airflow through the system is critical to calculate gas exchange and keep the $\Delta \mathrm{CO}_{2}$ readings within the IRGA's linearity range. Adjusting the flow rate with the butterfly valve placed beyond the restriction regulates the chamber's $\mathrm{CO}_{2}$ differential. Leaf temperature is also affected by chamber air circulation, which in turn is affected by flow rate.

Measuring air temperature and $R H$. Air temperature and $\mathrm{RH}$ are measured by exposing the PLC-B sensors to the air flowing in the ducts through the inlet and outlet adaptors (Fig. 2, location D). The sensors' response is rapid, taking only a few seconds to give a stable reading. The $\mathrm{RH}$ sensor must be calibrated for typical chamber values $>50 \% \mathrm{RH}$. The temperature and $\mathrm{RH}$ readings are influenced by the PLC-B's temperature, which may affect the calculation of assimilation rate, internal $\mathrm{CO}_{2}$, and, in particular, transpiration (Gucci and Corelli Grappadelli, 1989). It is therefore important not to expose the PLC-B to high light intensities, bearing in mind that the magnitude of the error induced by inac- 
curate temperature measurement varies according to the variable considered. For example, the mole flow of air decreases linearly with increasing temperatures (Fig. 3). However, at a measured flow of 20 liters $\cdot \mathrm{s}^{-1}$, errors of 1 or $5 \mathrm{C}$ in temperature measurement cause the air mole flow to be underestimated by $0.3 \%$ or $1.6 \%$, respectively (Fig. 3). As with the ADC system, air in the chamber is frequently 1 to $3 \mathrm{C}$ higher than ambient temperature because of the PLC-B's heat capacity and heat from the PLC-B's mixing fan. We do not consider a $1.6 \%$ change in the mole flow over a $5 \mathrm{C}$ error in air temperature measurement unacceptable in computing assimilation. If more accuracy is required, a digital thermohygrometer to measure temperature and $\mathrm{RH}$ instead of the PLC-B can be used.

Determining leaf area. We estimated leaf area based on previous, long-term records available for the trees used, or we removed all of the leaves and measured them with a LICOR 3000 leaf area meter (LI-COR, Lincoln, Neb.). If such information is unavailable and measuring all of the leaves impossible, sample leaf area or limit studies to paired observations on the same tree over a time interval short enough to avoid the effects of increased leaf area or different sun elevation, etc. Or, calibrate the experimental tree against a reference tree whose leaf area can be measured. By using two chambers to simultaneously measure the trees' Pn rate, the unknown leaf area can be estimated. Our experience, however, suggests that other factors, such as leaf distribution, play a role in the photosynthetic response. If the canopy structure is crowded, self-shading occurs; incontrast, where only a few leaves are present under high light intensities, a higher photosynthetic uptake will not occur. The need to determine leaf area, however, is debatable. Since the leaves experience different light levels due to their position in the canopy, we question whether referring canopy gas exchange to unit leaf area is a meaningful expression. Total gas exchange per tree or even gas exchange per unit light intercepted (as estimated by under-tree light measurements) may be a more meaningful expression, depending on the hypothesis tested.

2) Calibration. All data reported here were collected on 'Golden Delicious'/M.27 trees planted in 1981, trained to a slender spindle $\approx 2.0 \mathrm{~m}$ high, and spaced at $1.5 \times 0.75 \mathrm{~m}-\mathrm{a}$ density of 8889 trees/ha. The data were collected in Summer 1991, during which the trees were cropped normally.

Temperature. Three sets of temperature data were recorded: ambient air, by a shaded Crison T-637 thermometer (Crison, Barcelona, Spain); incoming and outgoing chamber air, by PLC-B sensor; and leaf and fruit surface temperature on a reference tree in open air and on the enclosed tree, by an infrared thermometer (Model 112C, Everest Interscience, Tustin, Calif.) held outside the chamber. Thermometer readings were checked for uniformity before use. The tree had been enclosed in the chamber for 10 days when the readings were taken on 5 and 6 Sept. 1991. Leaf temperature was measured by dividing the canopy in half according to height. A set of six readings at a time was taken from each half, first from the illuminated and then from the shaded portion of the canopy, until the standard deviation of the mean of all readings stabilized (i.e., only second decimal figures changed after a new set of readings was added). Since no differences were found in the upper and lower portions, the data were pooled and are presented as total mean values (Table 1).

Fruit temperatures were recorded by taking sets of readings from five exposed and five shaded pieces of fruit in the canopy. A similar data set was taken from the reference tree for leaves and fruit on 5 Sept. (Table 1). On 6 Sept., because the flow was raised from 10 to 20 liters $\cdot s^{-1}$ to reduce $\mathrm{CO}_{2}$ gradients in the chamber, the air and leaf temperatures in the chamber were measured again (Table 1). In general, chamber temperatures were higher than ambient temperature. Part of the fan's energy is transformed into heat by friction and turbulence, and additional heat may be released by the fan's motor, thus increasing air temperature by $\approx 3 \mathrm{C}$. As a result, leaves and fruit of trees inside chambers are warmer than leaves and fruit on trees outside (Table 1). In the chamber, however, evaporative cooling from transpiration resulted in leaves 1.4 to 1.7C cooler than the air, a temperature difference similar to that recorded for leaves in the open. When the flow rate was increased to 20 liters $\cdot \mathrm{s}^{-1}$, the leaves were cooler than at 10 liters $\cdot \mathrm{s}^{-1}$, even though the ambient and chamber air temperatures were slightly higher than on the previous day $(\approx 0.5 \mathrm{C})$. In general, fruit surface was considerably warmer than leaf surface, both inside the chamber and in the open, the difference being 4.0 to $4.5 \mathrm{C}$ (Table $1)$. This is to be expected, given the lower transpiration of the fruit.

Although the chamber puts a heat load on the tree, the magnitude of the temperature increase does not seem unacceptable and, in general, does not exceed a threshold of $\approx 3 \mathrm{C}$. Our data show that, even at high ambient air temperatures, transpiration seems to prevent large increases in leaf temperatures. This observation agrees with Adaros et al. (1989), who found that leaves in their chamber were warmer $(+3.6 \mathrm{C})$ than those outside, and indicated that such an increase was controlled by leaf transpiration. In our chamber, flow rate relative to total chamber volume was sufficient to remove the "greenhouse effect" heat generated. by the plastic cover. We estimate that 20 liters $\cdot \mathrm{s}^{-1}$ equal $\approx 1.5$ volume changes/ min. The small difference- $n$ average $0.5 \mathrm{C}-$ between inlet and outlet air recorded throughout could indicate such a heating effect, although limited. When measuring plants incapable of optimum transpiration, such as water-stressed trees, one would expect increased canopy heating inside the chamber due to reduced transpirative cooling.

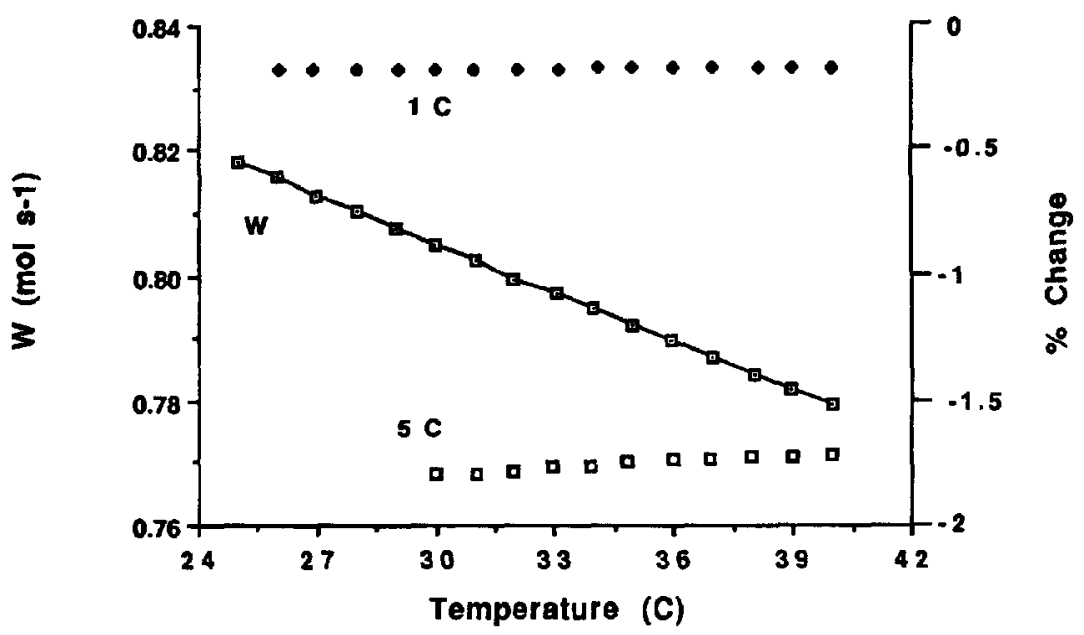

Fig. 3. Change in the mole fraction of air (W) as temperature increases from 25 to $40 \mathrm{C}$ at a measured flow of 20 liters. $\mathrm{s}^{-1}$ (line), and percent change in the mole fraction when errors of 1 (diamonds) and 5C (squares) are made in measuring air temperature over the same range.

Table 1. Air, leaf, and fruit temperature $\left(t,{ }^{\circ} \mathrm{C}\right)$ of a free-standing and an enclosed tree at two air flows under sunny conditions.

\begin{tabular}{|c|c|c|c|c|c|c|}
\hline \multirow[b]{2}{*}{ Tree } & \multirow{2}{*}{$\begin{array}{c}\text { Flow } \\
\left(\text { liter } \cdot s^{-1}\right)\end{array}$} & \multirow[b]{2}{*}{ Ambient $t$} & \multicolumn{2}{|c|}{ Chamber air } & \multirow{2}{*}{$\begin{array}{c}\text { Leaf } t \\
\text { (mean } \pm \mathrm{SD})\end{array}$} & \multirow{2}{*}{$\begin{array}{c}\text { Fruit t } \\
\left(\text { mean } \pm \mathrm{SD}^{2}\right)\end{array}$} \\
\hline & & & Inlet & Outlet & & \\
\hline Free-standing & - & 29.2 & - & $\overline{--}$ & $27.5^{y} \pm 2.58$ & $31.9 \pm 4.47$ \\
\hline Enclosed & 10 & 29.2 & 32.2 & 32.5 & $30.8^{x} \pm 1.92$ & $35.5 \pm 4.1$ \\
\hline Enclosed $^{w}$ & 20 & 29.9 & 32.6 & 33.0 & $29.0^{v} \pm 1.18$ & - \\
\hline
\end{tabular}

${ }^{2}$ Average of 10 readings.

"Average of 12 readings.

*Average of 36 readings.

"Readings taken on 6 Sept. 1991. Free-standing-tree data on that day not reported, as they were similar to those recorded on 5 Sept. 1991.

'Average of 24 readings. 
Carbon dioxide gradients. Carbon dioxide gradients in the chamber were measured by comparing readings from an empty chamber and one containing a tree. Both chambers were fitted with lines placed in various positions to sample air from different parts of the chamber volume. Because of the canopy, the number of positions from which air samples were drawn in the tree chamber was increased from five to seven (Fig. 1 and Table 2). The sampling lines were all the same length and connected one at a time to the IRGA's analysis channel. Air sampled from chamber inlet was continuously fed to the IRGA's reference channel. At a flow of 10 liters $\cdot \mathrm{s}^{-1}$, no gradients were found in the empty chamber, whereas the $\mathrm{CO}_{2}$ differential $\left(\mathrm{CO}_{2 \text { outer }}-\mathrm{CO}_{\text {2inter }}\right)$ in the chamber with a tree varied widely depending on position (same side or opposite the trunk from the inlet) and height in the chamber (Table 2). In the upper canopy and on the opposite side of the trunk relative to the inlet, the $\mathrm{CO}$ differential exceeded the region of the IRGA's linearresponse (Table 2, positions 1, 5, 6, G); increasing the flow to 20 liter $\cdot \mathrm{s}^{-1}$ greatly reduced the $\mathrm{CO}_{2}$ gradients. There seems to be good air mixing in the chamber at the larger flow.

Light quality. The intensity and the spectral composition of the radiation passing through the plastic film were checked with a LI-COR1800/22 spectroradiometer, holding the sensor and the film normal to the incoming radiation. Radiation intensity decreased $11.5 \%$ over the 300- to 1100-nm wavelength range, while the spectral composition was essentially unchanged (Fig. 4). The plastic's transmission characteristics seem satisfactory - the absorption is not large enough to be a limiting factor under most circumstances. Polyethylene was used because of its good spectral characteristics and because of practical advantages of working with it, i.e., it fit to the tree shape easily. This material is not the most appropriate choice with respect to $\mathrm{CO}_{2}$ and $\mathrm{H}_{2} \mathrm{O}$ permeability, although at the air flows used (1.5 volume changes/min), the loss resulting from such permeability may not be of great concern. Mylar, which has better permeability characteristics, could be used instead. Both materials, however, are likely to change the direct : diffuse proportion of light incident on the tree. Although we did not measure the amount of this change, one should be aware of the possibility of deviations from ambient light conditions, especially during bright days. In this instance, the stiffer mylar might have a worse effect in that it tends to "wrinkle" and therefore scatter the radiation more than the flatter polyethylene.

3) Light responses. Studies at ambient and high $\mathrm{CO}_{2}$ concentrations were carried out between 11:30 and 13:30 HR on clear sunny days. Decreasing light levels were attained by covering the chamber with neutral shadecloth of varying intensity. At each shade intensity, after IRGA stabilization (typically 5 to 10 $\mathrm{min})$, two readings were taken. At light intensities of 350 to $400 \mu \mathrm{mol} \cdot \mathrm{m}^{-2} \cdot \mathrm{s}^{-1}$, the flow rate was reduced from 18.4 to 2.3 liter $\cdot \mathrm{s}^{-1}$ to detect respiration. The decrease in flow did not alter the temperature reading and was assumed not to interfere with assimilation. The light response at high $\mathrm{CO}_{2}$ was tested by bleeding pure $\mathrm{CO}_{2}$ into the inlet stream to give a steady reading of $900 \pm 10 \mathrm{ppm} \mathrm{CO}_{2}$. The light response was determined after $2 \mathrm{~h}$ of such conditioning. Data were analyzed according to the model Pn = B0[B1 - exp $(-\mathrm{B} 2 \times$ PAR $)]($ Fig . $5)$, where $\mathrm{B} 0, \mathrm{~B} 1$, and $\mathrm{B} 2$ represent estimated parameters. The fit of the model is good: $R^{2}=$ 0.94 for the curve at ambient $\mathrm{CO}_{2}$. The compensation point is higher than the values indicated for individual leaves, occurring, according to the model, at $140 \mu \mathrm{mol} \cdot \mathrm{m}^{-2} \cdot \mathrm{s}^{-1}$, while saturation was recorded at $\approx 1200 \mu \mathrm{mol} \cdot \mathrm{m}^{-2} \cdot \mathrm{s}^{-1}$. At high $\mathrm{CO}_{2}$ concentrations, the compensation point was reached at lower light intensity (40 $\left.\mu \mathrm{mol} \cdot \mathrm{m}^{-2} \cdot \mathrm{s}^{-1}\right)$. The saturation point was not reached over the tested range of light intensities.

The experience gained after extended testing leads us to believe that the system we describe here is reliable. Our data on healthy trees indicate that the conditions in the chamber do not substantially deviate from ambient

Table 2. Differential $\mathrm{CO}_{2}\left(\Delta \mathrm{CO}_{2}\right)$ concentrations between inlet and outlet readings at several positions in an empty chamber and one with a tree. Average inlet $\mathrm{CO}_{2}$ concentration was 340 $\mathrm{ppm}$. Readings in the chamber were taken at two flow rates. Position from which the sample was drawn refers to the $\mathrm{CO}_{2}$ sampling sites as shown in Fig. 1.

\begin{tabular}{lccc}
\hline & \multicolumn{3}{c}{$\Delta \mathrm{CO}_{2}(\mathrm{ppm})$} \\
\cline { 2 - 4 } & $\begin{array}{c}\text { Empty } \\
\text { chamber }\end{array}$ & \multicolumn{2}{c}{$\begin{array}{c}\text { Chamber } \\
\text { with tree }\end{array}$} \\
\cline { 3 - 4 } Position & $\left(10\right.$ liters-s $\left.^{-1}\right)$ & 10 liters $\cdot \mathrm{s}^{-1}$ & 20 liters $\cdot \mathrm{s}^{-1}$ \\
\hline 1 & -1 & -47 & -32 \\
2 & -2 & -26 & -27 \\
3 & --- & -31 & -33 \\
4 & --- & -30 & -32 \\
5 & -1 & -64 & -39 \\
6 & -1 & -72 & -32 \\
$\mathrm{G}$ & -1 & -64 & -33 \\
\hline
\end{tabular}

conditions, and thus allow the trees to be enclosed for long periods of time (up to 4 months, in our experience) without altering their function. The light-response curves indicate good system sensitivity to environmental changes. These results exemplify the studies made possible by this system in the field, such as training system comparisons and wholetree mass balances. However, several areas need particular attention and improvement.

- Air temperature increases as it flows through the system, causing a temperature difference with respect to ambient temperature. This difference can be a concern for predawn or night readings, when the effect of such heat transfer elicits abnormal temperature and $\mathrm{RH}$ values in and out of the chamber.

- Water condensation on the chamber wall is of concern, but constitutes a small fraction of the total amount lost by the tree and adds up to perhaps no more than a few grams of water per hour as opposed to the more than 1 liter $\cdot \mathrm{h}^{-1}$ a tree may lose (E.M., unpublished data).

- Chamber shape and air flow affect condensation-a considerable flow and smoothly tapered profile improve air circulation, thereby reducing the amount of air hovering around the outlet before leaving the chamber.

- Sealing the bag is important, yet not critical. This open system is slightly pressurized, and air is more likely to escape from rather than enter the chamber, with little effect on the readings.

- This system is manually operated and thus does not continuously (i.e., day and night) and automatically monitor tree gas exchange. Although such monitoring can be achieved by a slightly different approachone based on a PC that controls a more automated system, our objectives were to provide a simple, inexpensive gas-exchange

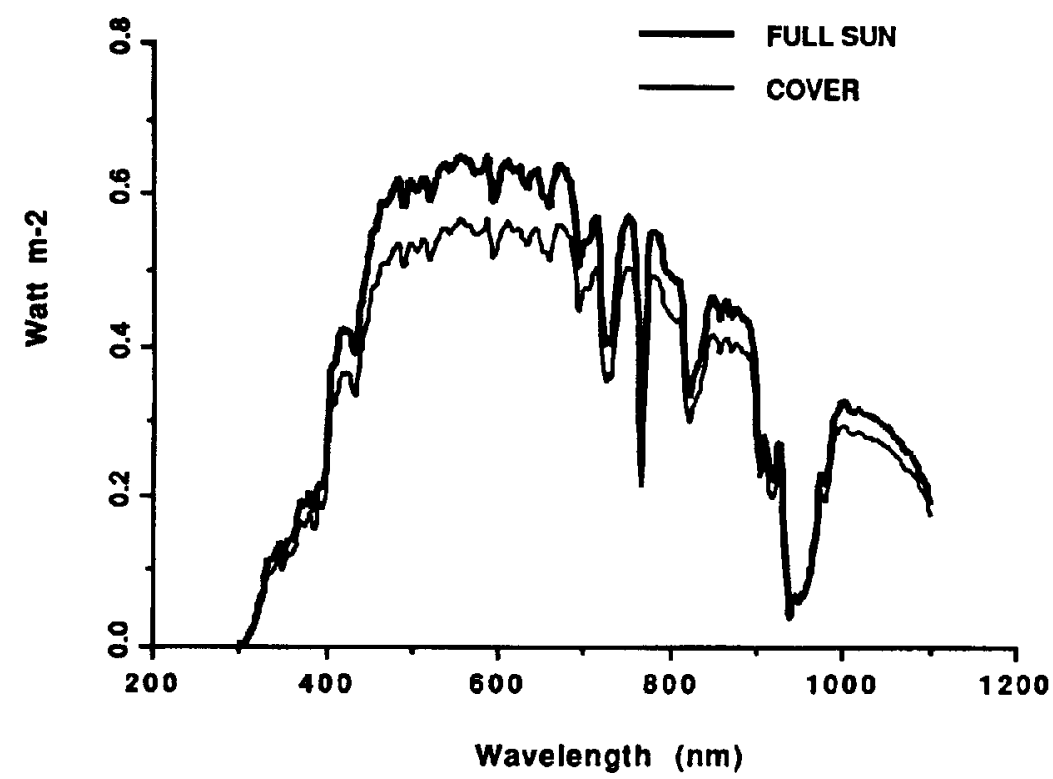

Fig. 4. Spectral composition of sunlight, outside and inside the plastic chamber. 


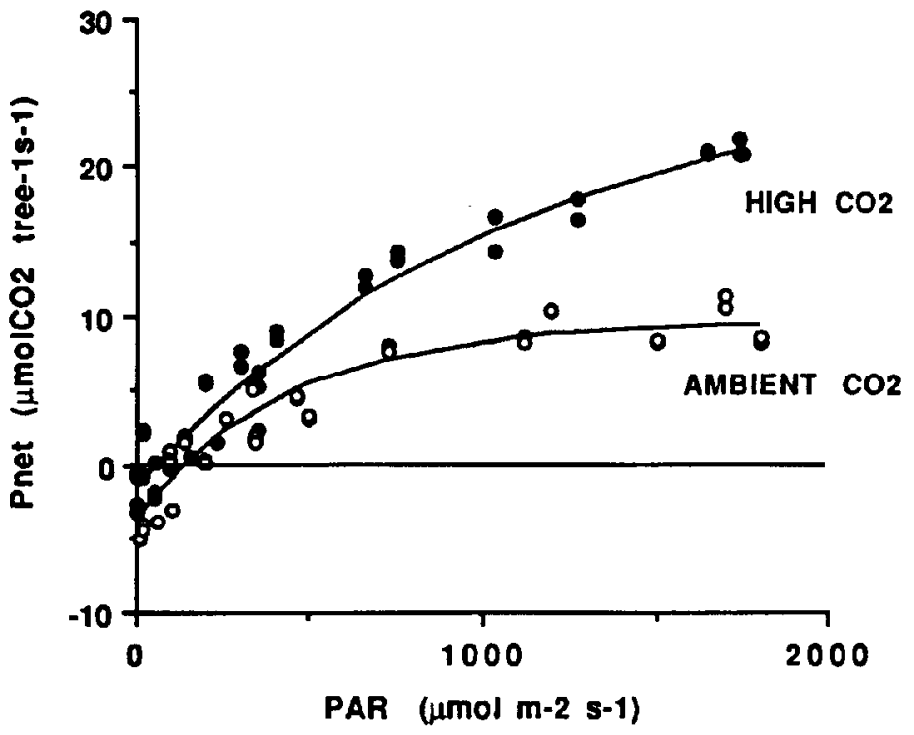

Fig. 5. Photosynthetic response curves to light incident upon the chamber for an 11-year-old 'Golden Delicious'M.27 tree at ambient $(0)$ and high $(900 \pm 10 \mathrm{ppm})(\bullet) \mathrm{CO}_{2}$ concentrations.

system for whole trees in the field using a commercially available photosynthesis unit and test its reliability. A major reason for constructing such a system is that measuring whole-tree gas exchange is, in many cases, more desirable than extrapolating single-point data to whole canopies.

While far from attaining optimum solutions to the problems involved, we think that the system proposed here can be used satisfactorily for horticultural and physiological fruit tree studies. In particular, since tree chamber number depends only on fan power, this sys- tem could monitor several trees at a time, thus permitting appropriate statistical designs (i.e., blocking, replications, etc.) to be applied to hypothesis testing involving whole trees.

\section{Literature Cited}

Adaros, G., H.J. Weigel, and H.J. Jäger. 1989. Environment in open-top chambers and its effects on growth and yield of plants. I. Measurement of microclimatic parameters. Gartenbauwissenschaft 54(4):165-171.

Flore, J.A. and A.N. Lakso. 1990. Environmental and physiological regulation of photosynthesis in fruit crops. Ann. Rev. Hort. Sci. 11:111-157.
Grace, J. 1989. Measurement of wind speed near vegetation, p. 57-73. In: R.W. Pearcy, J. Ehleringer, H.A. Mooney, and P.W. Rundel (eds.). Plant physiological ecology. Chapman and Hall, London.

Gucci, R. and L. Corelli Grappadelli. 1989. Misura della fotosintesi. II. Campi di applicazione e problematiche relative al materiale vegetale e alle condizioni ambientah (English summary). Frutticoltura 51(12):75-80.

Heagle, A.S., D.E. Body, and W.W. Heck. 1973. An open top field chamber to assess the impact of air pollution on plants. J. Environ. Qual. 2:365368.

Heinicke, A.J. and N.F. Childers. 1937. The daily rate of photosynthesis, during the growing season of 1935, of a young apple tree of bearing age. Cornell Univ. Agr. Expt. Sta., Ithaca, N.Y., Mem. 201.

Long, S.P. and J.E. Hallgren. 1985. Measurement of $\mathrm{CO}_{2}$ assimilation by plants in the field and in the laboratory, p. 62-94. In: J. Coombs, D.O. Hall, S.P. Long, and J.M.O. Scurlock (eds.). Techniques in bioproductivity and photosynthesis. Pergamon Press, Oxford, U.K.

Osborne, W.C. 1977. Fans. 2nd ed. Pergamon Press, Oxford, U.K.

Sirois, D.L. and G.R. Cooper. 1964. The influence of light intensity, temperature and atmospheric carbon dioxide concentration on the rate of apparent photosynthesis of a mature apple tree. Maine Agr. Expt. Sta., Orono, Bul. 626.

Snelgar, W.P., G.S. Bayley, and P.J. Manson. 1988. Temperature studies on kiwifruit vines using relocatable greenhouses. N.Z. J. Expt. Agr. 16:329-339.

Weinstock, L., W.J. Kender, and R.C. Musselman. 1982. Microclimate within open-top air pollution chambers and its relation to grapevine physiology. J. Amer. Soc. Hort. Sci. 107:923929.

Wibbe, M. and F. Lenz. 1989. Wieviel $\mathrm{CO}_{2}$ nimmt ein apfelbaum an heißen tagen im sommer auf? (English summary) Erwerbsobstbau: 88-90. 